\title{
In the Dressing Room
}

\section{Deb Waterhouse-Watson}

\begin{abstract}
Above the roar of the shower floats a light singing voice, a song whose words are lost amongst the flood of droplets. Smells of shampoo and cleanliness waft into a cavernous dressing room lit by a thousand glowing bulbs. Powders, pots, bottles and brushes are arranged neatly on a long dressing table stretching out below a mirror on the wall. The carpet is scuffed and faded, the room painted a non-descript wall colour; the paint is peeling slightly under the dressing table and behind the door, but no-one ever looks there, really. Abruptly, both singing and shower cut off.
\end{abstract}

Clouds of steam and mist cast the room in a faintly eerie gloom and into this a slender figure emerges, clad in a purple towel, with longish black hair hanging wetly across thin shoulders. The towel is soon discarded in favour of more appropriate attire and a stool before the mirror quickly attained. The mirror is clouded and 
saturated with condensation, reflecting only the shadow of a face framed by wisps of darker hair. A well-manicured hand selects a brush and sets to work. Though small, the hand is not exceptionally delicate; the fingers are not especially long, nor especially thin. Yet there is music flowing in them.

Gradually, that shadowed outline of a face takes on definition; as practised hands move without thought, a red painted mouth appears. The lips make an ' $O$ ' and part to reveal white teeth, perfect except for one slightly crooked canine in the bottom row and a small stain on another which is only visible in the wrong light. Spots of colour bloom on white cheeks, and eyelashes grow outwards, long and dark, each individual lash becoming clear against the pale skin. A splash of colour blossoms above one line of black, a liquid aquamarine which sparkles and glints, then the same brush floods the other lid with blue. The damp black locks lift, expand, settle in formation under waves of heat blasting from a hairdryer. Both lids close as gold glitter rains down, settling on hair, face, neck, clothes. The fog lifts, and suddenly, shockingly, the eyelids flick open to reveal two grey-blue eyes staring candidly out of the cold glass.

A disembodied voice calls, 'You're on in five, Brian.' The face in the mirror smiles. Brian brushes glitter off his pants, pulls his shirt straight and runs a blue-emblazoned eye over the instruments arranged against the wall. He straps on a guitar, strums a chord, and strides out onto the stage. 